\title{
Serviço Social e socioeducação nas regióes Oeste e Centro-Oeste do Paraná
}

\author{
Social work and socio-education \\ in Western and Midwestern Paraná
}

Terezinha Ferraz*

Eugênia Aparecida Cesconeto**

\begin{abstract}
Resumo - Esta produção é resultado de pesquisa realizada como requisito parcial para conclusão do curso de Mestrado em Serviço Social pela Unioeste, campus de Toledo. O objetivo é analisar a intervenção do assistente social no âmbito da Socioeducação nas regiões Oeste e Centro-Oeste do estado do Paraná. A pesquisa pautou-se na abordagem qualitativa a partir de teoria crítica, pois esta possibilita que se abordem os significados através de uma interpretação dinâmica da realidade. Para obtenção dos dados que possibilitaram responder ao objetivo da pesquisa, foram utilizados os seguintes procedimentos metodológicos: pesquisa bibliográfica, análise documental e pesquisa de campo. O universo da pesquisa foi constituído de oito assistentes sociais, delimitando-se a amostra de quatro profissionais. Os dados foram coletados através da entrevista semiestruturada, utilizando-se do formulário de entrevista, entre outubro e novembro de 2014. Como categorias de análise, foram definidas: intervenção profissional e defesa de direitos.

Palavras-chave: Serviço Social; intervenção profissional; socioeducação.

Abstract - This paper is the result of a research done as part of a Master's degree in Social Work at the Universidade Estadual do Oeste do Paraná (Unioeste) at Toledo. Its goal is to analyze the social worker's intervention on socio-education at the Western and Midwestern regions of the Brazilian state of Paraná. The research uses critical theory and a qualitative approach, because this allows an approach to meaning through the dynamic interpretation of reality. To obtain the data, the following methodological procedures were used: bibliographic research, documentary analysis, and field research. The universe for this research consisted of eight social workers, focusing
\end{abstract}

\footnotetext{
* Assistente Social. Mestre pela Universidade Estadual do Paraná (UNIOESTE). Correspondência: Rua Olindo Periolo, n. 1356, bairro Pacaembu, Cascavel/PR. CEP: 85.816-330. Email:<ter.m.ferraz@gmail.com>.

** Assistente Social. Doutora. Professora Associada do Curso de Serviço Social, do Programa de Mestrado em Serviço Social e do Programa de Pós-graduação em Desenvolvimento Regional e Agronegócio da UNIOESTE. Líder do Grupo de Pesquisa e Defesa dos Direitos Humanos Fundamentais da Criança e do Adolescente. Correspondência: Rua da Faculdade, 645, Jd. La Salle, Toledo/PR. CEP: 85.903-000. Email: <eugeniacesconeto@uol.com.br>.
} 
on a sample of four professionals. Data was collected through semistructured interviews, using the interview form, between October and November 2014. The categories of analysis chosen were professional intervention and advocacy.

Keywords: social work; professional intervention; socio-education.

\section{Introdução}

A proposição do tema envolvendo o profissional de Serviço Social junto a adolescentes privados de liberdade nos centros de socioeducação (Cense 1 e Cense 2) nas regiões Oeste e Centro-Oeste do estado do Paraná decorre das inquietudes vividas por um período de aproximadamente nove anos de atuação nestas duas unidades quando, por vezes, tornaram-se evidentes situações violadoras de direitos, principalmente em relação ao princípio da dignidade humana.

Em tal realidade institucional, o cumprimento do critério socioeducativo de internação, que se constitui em medida privativa de liberdade de adolescentes que cometeram ato infracional de natureza grave (BRASIL, 1990, p. 59), a partir da previsão legal, estava muito aquém do mínimo necessário para um padrão de convivência digna nesses tipos de espaço. Os adolescentes eram confinados em locais insalubres, sem condições adequadas de higiene, com celas expostas às condições climáticas e, geralmente, não respeitando a capacidade comportada pelo espaço.

Além disso, procedia-se o isolamento nas chamadas "solitárias", espaços físicos muito pequenos, nos quais um adolescente podia permanecer por várias horas, durante o dia ou a noite, até que o seu "comportamento" estivesse de acordo com o exigido e fosse compatível com as regras previstas pelo sistema institucional.

Sob essas condições, outras formas de violências não eram incomuns, porém, a ideia que circulava no interior do ambiente organizacional era de que a ilicitude do ato praticado pelo adolescente invertia sua condição de ser e de estar. A partir de sua inclusão no sistema de privação de liberdade, sua história e seu potencial de superação costumavam ser completamente desconsiderados. A afirmação "ele é um bandido" expunha o contrassenso das situações de internação que, na maioria das vezes, é de natureza leve e a punição pesada demais para o ato cometido.

Passados nove anos, pode-se dizer que, no estado do Paraná, algumas dessas condições evidenciadas no período compreendido entre janeiro de 2006 e janeiro de 2007 sofreram alterações, tanto no que concerne à estrutura física, que passa a ter um padrão arquitetônico exigido para a construção de novas unidades, quanto à metodologia de trabalho, 


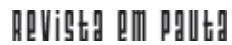

\} SERVIÇO SOCIAL E SOCIOEDUCAÇÃO - FERRAZ, T.; CESCONETO, E. A. \}

DOI: $10.12957 /$ REP.2016.27864

que tem sido pensada a partir da previsão legal: Constituição Federal de 1988 (BRASIL, 1988), Estatuto da Criança e do Adolescente 1990 e, mais recentemente, Sistema Nacional de Atendimento Socioeducativo (Sinase) previsto na resolução n. 119 de 2006 do Conanda e Lei12.594 de 2012 (BRASIL, 2006)

A promulgação dessas legislações, apesar de todos os limites para a sua aplicabilidade, foi fundamental para o processo de formulação da base jurídica dos direitos de cidadania e para o estabelecimento das diretrizes para o atendimento da criança e do adolescente, sob a perspectiva da doutrina da proteção integral. Para o adolescente autor de ato infracional, em cumprimento de medida socioeducativa, possibilitou o reconhecimento de sua condição de sujeito, logo, devendo ser tratado com respeito e dignidade.

Com isso, um novo modo de intervir junto a esse público tem ganhado contornos, especialmente no Paraná, em que a socioeducação vai sendo pensada com a promessa de melhorias das condições citadas, cujos objetivos coadunavam com a previsão legal. A construção de novas unidades socioeducativas, a contratação de pessoal e o ciclo de capacitações oferecidas aos novos funcionários a partir de agosto de 2006 são exemplos do movimento feito a partir dessa nova concepção.

Atualmente, no estado do Paraná encontram-se em funcionamento 18 Censes, sendo que nove deles executam apenas a medida socioeducativa de internação. Dentre esses, um é destinado ao atendimento do público feminino, seis são mistos e três atendem apenas a internação provisória'. Focando-se no recorte da pesquisa, tem-se, na região Oeste, três Censes instalados nos municípios de Cascavel, de Foz do Iguaçu e de Toledo, sendo que todos atendem os adolescentes sentenciados à internação. Na região Centro-Oeste, há um Cense situado em Laranjeiras do Sul.

As unidades participantes da pesquisa se estruturam da seguinte forma: Cascavel 2 e Laranjeiras do Sul foram inauguradas em 2007 e contam com o mesmo modelo arquitetônico, com ambientes adequados ao cumprimento das finalidades de cada área específica, como salas de aula, teatro de arena, ginásio de esportes, espaço ecumênico, alojamentos individuais, entre outros. Sua capacidade de atendimento é de 78 adolescentes sentenciados ao cumprimento da medida socioeducativa de internação. Tanto a estrutura arquitetônica quanto a proposta pedagógica atendem às especificações da Resolução n. 119/2006 do Conselho Nacional dos Direitos da Criança e do Adolescente (Conanda) e da Lei n. 12.594/2012, que dispõe sobre o Sinase, além da Lei n. 8.069/1990, que dispõe sobre o Estatuto da Criança e do Adolescente (BRASIL, 1990).

A unidade de Foz do Iguaçu, inaugurada em 1998, foi a primeira da região a atender adolescentes autores de ato infracional. Atualmente

${ }^{1}$ A internação provisória está prevista no Artigo 183 do Estatuto da Criança e do Adolescente. 


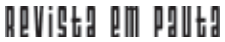

\} SERVIÇO SOCIAL E SOCIOEDUCAÇÃO - FERRAZ, T.; CESCONETO, E. A. \}

DOI: 10.12957/REP.2016.27864

são atendidos nesse espaço 100 adolescentes, em alojamentos coletivos, sendo que apenas 54 vagas são destinadas à internação; as demais são destinadas à internação provisória. A proposta pedagógica é a mesma dos Censes de Cascavel e de Laranjeiras do Sul, mas adequada à realidade daquele espaço.

O Cense de Toledo, segundo Pizato (2011), existe desde 1981, quando foi criado o $20^{\circ}$ Batalhão de Polícia Civil do Município. Nesse espaço, em uma pequena cela, os "menores" eram atendidos. Em 1998 foi fundado o Centro Único de Atendimento à Criança e ao Adolescente (Cuaca), anexo ao batalhão, que passou a atender adolescentes autores de ato infracional. No ano de 2000, a Prefeitura Municipal de Toledo assumiu o referido centro, que passou a ser chamado de Centro de Atendimento ao Adolescente Infrator (Ceaadi).

Já em 2006, com a reestruturação do sistema socioeducativo, esta unidade passou a se chamar de Cense. O espaço continua o mesmo, porém, houve algumas adequações em decorrência de reformas realizadas durante os últimos anos. Essa unidade dispõe de alojamentos coletivos, com capacidade para atender 25 adolescentes, e segue os parâmetros pedagógicos das demais unidades. No entanto, assim como a unidade de Foz do Iguaçu, apresenta dificuldades que acabam ferindo os direitos do adolescente.

Nesse contexto de realidades complexas e desafiadoras, a intervenção do assistente social se desenvolve num palco de constantes enfrentamentos, dadas as relações de poder e o jogo de disputas e de interesses que se colocam contrários à perspectiva de defesa de direitos. Refletir sobre essa prática, nesse contexto, é por si só um desafio, pois exige um repensar sobre o processo interventivo diante dos requisitos postos pelo projeto éticopolítico da profissão, ao mesmo tempo em que pressupõe a construção de possibilidades de interações pautadas pelas dimensões do respeito à dignidade humana e à garantia de direitos.

Nesse sentido, elencou-se como problemática a que a pesquisa se propõe a responder: em que medida a intervenção do assistente social contribui para a efetivação dos direitos do adolescente privado de liberdade, quando do cumprimento de medida socioeducativa de internação em centros de socioeducação?

Para compreender as questões que estão envoltas na prática do assistente social nesses espaços, estabeleceu-se como objetivo analisar a intervenção desse profissional no âmbito da socioeducação nas unidades de internação de adolescentes, nas regiões Oeste e Centro-Oeste do Estado do Paraná. Partindo disse pressuposto, buscou-se: 1 ) identificar o perfil dos profissionais e seu espaço de intervenção nas unidades socioeducativas; 2) contextualizar a universalidade dos direitos humanos e seus reflexos na política da criança e do adolescente no Brasil; 3) analisar o movimento do Serviço Social na perspectiva da defesa de direitos. 


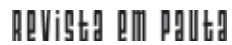

\} SERVIÇO SOCIAL E SOCIOEDUCAÇÃO - FERRAZ, T.; CESCONETO, E. A. \}

DOI: $10.12957 /$ REP.2016.27864

Para obter os dados que possibilitaram responder ao problema da pesquisa, foram utilizadas, como procedimentos metodológicos, pesquisas bibliográficas de campo e documental.

O desenvolvimento desse trabalho se deu na abordagem metodológica de estudo de caso, a qual mostrou-se como a mais adequada para um tipo de estudo que se atém a universos restritos, como o de pequeno grupo de profissionais assistentes sociais que atuam nos centros de socioeducação da região Oeste e Centro-Oeste do Paraná. Essa abordagem é relevante porque se "assenta numa pesquisa intensiva e aprofundada de um determinado objeto de estudo, que se encontra extremamente bem definido e que visa compreender a singularidade e globalidade do caso em simultâneo" (COUTINHO, 2008, p. 22).

O universo da pesquisa foi composto por oito assistentes sociais com análise de amostra de quatro profissionais entrevistados, tendo em vista que as mesmas mostraram a incorporação do discurso institucional, tornando-se muito similares nas respostas dos sujeitos. Os dados foram coletados por meio de entrevista semiestruturada, utilizando-se do formulário de entrevista aplicado entre os meses de outubro e novembro de 2014 e organizado por eixos. No primeiro, buscou-se contextualizar a universalidade dos direitos humanos e seus reflexos na política da criança e do adolescente na perspectiva da proteção integral. No segundo eixo, propôs-se uma análise do movimento do Serviço Social na perspectiva da defesa de direitos. Já o terceiro eixo objetivou o estabelecimento de um debate sobre a socioeducação no estado do Paraná a partir de uma perspectiva de defesa de direitos na concepção do profissional de Serviço Social. No processo de construção da pesquisa, duas categorias de análise perpassaram a construção desse trabalho, quais sejam: a intervenção profissional do assistente social e a defesa de direitos.

Com base nisso pautou-se a análise qualitativa da pesquisa, a partir de teoria crítica, considerando que ela trabalha com os significados das ações por meio de uma interpretação dinâmica da realidade e das relações que se ocultam nas estruturas sociais.

A pesquisa trouxe como resultado que a intervenção do assistente social, no âmbito da socioeducação, tem como horizonte a perspectiva da defesa de direitos humanos, contudo, demonstra que a promulgação de uma lei não contempla o ser humano em sua generalidade, como também não se constitui em garantia de acesso a esses direitos. O posicionamento desse profissional, em favor do usuário do sistema socioeducativo, apesar da evidência dos limites institucionais vivenciados e demonstrados na pesquisa, constitui-se num processo desafiador, uma vez que busca se contrapor às questões violadoras de direitos e que ferem o princípio da dignidade humana.

As reflexões registradas pelos relatos dos profissionais revelam, de modo significativo, situações complexas de violação de direitos que 


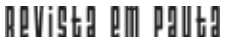

\} SERVIÇO SOCIAL E SOCIOEDUCAÇÃO - FERRAZ, T.; CESCONETO, E. A. \}

DOI: $10.12957 /$ REP.2016.27864

ainda persistem no cotidiano das unidades socioeducativas. Nesse sentido, tecem considerações em relação aos avanços e às melhorias nas condições de atendimentos ao adolescente autor de ato infracional, mas denunciam o distanciamento entre um direito positivado e aquilo que realmente é concretizado.

\section{O sistema socioeducativo no Brasil na perspectiva da proteção integral}

O atendimento socioeducativo destinado aos adolescentes autores de ato infracional, na perspectiva dos direitos humanos, tem seu marco a partir das legislações de âmbito nacional e internacional. No Brasil, a promulgação da Constituição Federal de 1988 e do Estatuto da Criança e do Adolescente possibilitaram a implantação do Sistema Nacional de Atendimento Socioeducativo (Sinase) entre 2006 e 2012. Não há como desconsiderar, no entanto, o percurso percorrido desde o Código de Menores até as referidas legislações. Ao mesmo tempo, faz-se necessário compreender em que circunstâncias e condições históricas essas normativas se fizeram presentes.

As discussões versando sobre o atendimento a esse público e as formas de assistência aos "menores" abandonados são materializados, segundo Cossetin (2012), no primeiro Código de Menores de 1927.

Com a promulgação desse código instituiu-se um novo entendimento sobre a infância, no qual se sobressaíram duas categorias de crianças: as pertencentes as uma determinada família e as abandonadas. "E ainda nesse segundo abstrato se encontra outra divisão: entre os abandonados coitadinhos, recém-nascidos e os menores perigosos que precisam ser recuperados" (TRINDADE apud COLOMBO, 2006, p. 84). Eram penalizados aqueles que não se adequavam ao sistema de normas estabelecidas pelos dogmas da igreja ou à filosofia das entidades que os assistiam. A função assistencial, nesse contexto, era apenas simbólica, considerando a inexistência de ações legais para todas as crianças e adolescentes. Filhos de escravos, negros e desprovidos de condições financeiras não eram reconhecidos como sujeitos dignos ao exercício da cidadania, ficando sempre à mercê do auxílio dos programas assistencialistas.

A partir dessa concepção, o governo investia cada vez mais na organização do aparato policial, sendo que os dirigentes do Estado eram nomeados pela Ditadura Militar, sistema que se responsabilizava em dar continuidade ao controle social de forma rígida e repressiva. A pobreza era analisada e tratada como caso de segurança nacional, logo, crianças e adolescentes mais desprovidos economicamente estavam sempre à mercê de tais comandos (COSSETIN, 2012).

A construção social e ideológica desse código propiciava 
[...] o enquadramento do público infanto-juvenil pobre na categoria de menor. Uma vez categorizado pejorativamente neste grupo, estava sujeito ao cumprimento de normas legais que previam a sua inserção no trabalho desde tenra idade, o que iria ajudar em sua recuperação e diminuir sua periculosidade. Esses objetivos seriam alcançados por meio da disciplina e do trabalho. Assim, se reeducariam os moralmente abandonados e até mesmo os que cometiam crimes. (COSSETIN, 2012, p. 74).

O Código de Menores previa plenos poderes para que os juízes aplicassem as penalidades julgadas pertinentes àqueles que cometiam determinados crimes e que, além disso, destituíssem o "pátrio poder" dos que se encontravam em situação não condizente com os parâmetros societários naquele período. Normalmente, a medida mais frequentemente tomada era a de colocar as crianças e os adolescentes sob a tutela do Estado. E, sob justificativa de zelar pela sua proteção, muitas delas foram institucionalizadas e perderam completamente o referencial de relação familiar.

Essa lei instituía uma intervenção fundamentada, segundo Zaniani (2012), no binômio carência-delinquência e estabelecia diretrizes para o trato com a infância e a juventude de uma determinada classe social. Além disso, regulamentava "questões que iam desde as medidas a serem aplicadas aos menores abandonados, aos delinquentes, à regulamentação do trabalho infantil, até sobre a tutela [...] e a liberdade vigiada" (ZANIANI, 2012, p. 65).

No ano de 1979 foi instituído o segundo Código de Menores que, a partir das considerações de Colombo (2006), previa uma conexão em nível estadual entre o Judiciário, a Assistência Social e o Instituto de Assistência ao Menor (IAM), estabelecendo um corpo técnico para realizar a triagem dos adolescentes para posterior internamento. Contudo, foi somente a partir da promulgação da nova Constituição Federal, em 1988, das declarações internacionais e das lutas dos movimentos sociais que houve a indicação da necessidade de criação de uma lei que substituísse o Código de Menores.

Assim, em 1990, foi promulgado o Estatuto da Criança e do Adolescente, que estabelece as novas diretrizes para as ações destinadas a esse público, especificando as medidas socioeducativas cabíveis ao adolescente que praticou um ato infracional. No entanto, respeitando sua condição de especial desenvolvimento.

A partir do que preconiza o capítulo IV, nos artigos 112 ao 128 do estatuto, as medidas socioeducativas constituem-se em advertência, reparação do dano, prestação de serviços à comunidade, liberdade assistida, semiliberdade e internação. Estas têm como objetivos:

I - a responsabilização do adolescente quanto às consequências lesivas do ato infracional, sempre que possível incentivando a sua reparação; II - a integração social do adolescente e a garantia de seus direitos individuais e sociais, por meio do cumprimento de seu plano individual 
de atendimento; e III - a desaprovação da conduta infracional, efetivando as disposições da sentença como parâmetro máximo de privação de liberdade ou restrição de direitos, observados os limites previstos em lei. (BRASIL, 2012b, n.p.).

A medida socioeducativa de internação, prevista no artigo 121 do estatuto, constitui-se em "medida privativa da liberdade, sujeita aos princípios de brevidade, excepcionalidade e respeito à condição peculiar de pessoa em desenvolvimento" (BRASIL, 1990). Desse modo, é diferente dos conceitos previstos no Código de Menores, que seguiam uma linha de arbitrariedade e repressão, sendo a punição o único meio considerado possível para a "recuperação" desses adolescentes.

No entanto, ainda que o estatuto apresentasse propostas de mudanças significativas em ralação às intervenções voltadas a esse público, as propostas se limitavam ao plano jurídico-formal, não chegando ao seu destinatário de maneira efetiva. Evidenciavam-se situações em que adolescentes cumpriam suas sentenças em locais que, além de possuírem estruturas físicas precárias e inadequadas para alojá-los, também não dispunham das demais condições básicas e necessárias (alimentação, vestimentas, acesso à saúde, entre outras) ao desenvolvimento da dignidade humana. Tais aspectos ainda denotam uma cultura repressiva/punitiva que afeta especialmente a população jovem, negra e pobre que constantemente tem seus direitos violados.

Ainda que com limitações e sem resultados muito expressivos, o estatuto tem possibilitado novos direcionamentos na política da criança e do adolescente. É a partir dessa lei que o adolescente autor de ato infracional tem um espaço, o qual resultará em ações especificas que serão previstas no Sinase no ano de 2006, através da Resolução n. 119 do Conselho Nacional dos Direitos da Criança e do Adolescente (Conanda) e, em 2012, com a promulgação da Lei n. 12.594. Esta se constitui num guia para a implementação das medidas socioeducativas já estabelecidas pelo estatuto em 1990 (BRASIL, 2012b, p. 13).

O Sinase é entendido como um "conjunto ordenado de princípios, regras e critérios que envolvem a execução de medidas socioeducativas, incluindo-se [...] os sistemas estaduais, distrital e municipais, bem como todos os planos, políticas e programas" (BRASIL, 2012b, p. 137). Além disso, é direcionado especificamente para adolescentes em conflito com a lei, possibilitando que as medidas socioeducativas previstas no estatuto se tornassem mais concretas. A partir disso, uma nova concepção sobre socioeducação vai sendo discutida.

Compreende-se que, enquanto terminologia, a socioeducação é algo incipiente, sendo muitas vezes restringida a um significado reduzido de espaço da educação voltada para a coletividade e que, embora se constitua num direito, 
[...] é ainda entrecortada por muitas ambiguidades e contradições. Assim para efetivar tal especificação, é possível deparar-se com a seguinte subdivisão: uma de 'caráter mais protetivo' (para os que não transgrediram as regras sociais e cujas existências sociais estão no liame da ameaça ou violação de direitos) e outra de 'caráter mais socioeducativo', que se destina aos adolescentes que cometeram atos infracionais, para os quais a socioeducação deve visar promover uma formação educacional que permita integrá-los, satisfatoriamente, ao convívio social. (BIDARRA; ROESLER, 2011, p. 13-14)

Nesse sentido, a promulgação do Sinase trouxe avanços importantes que vão se constituindo no âmbito da regulamentação do processo de execução, incluindo outras dimensões de sua intervenção (financiamento do sistema, controle de gestão etc.) voltadas a esse público. A lei cria condições possíveis para que o adolescente em conflito possa ser considerado como sujeito que tem prioridade absoluta por estar em condição peculiar de desenvolvimento e, assim sendo, digno ao exercício da cidadania.

Seguindo ainda as considerações de Bidarra e Roesler (2011, p. 14), para "o Sinase a socioeducação pressupõe a capacidade de ofertar a experimentação, a participação em um projeto social compartilhado cujo fundamento seja o da constituição autônoma do ser social". Dessa forma, a participação do adolescente na vida em sociedade, face a uma perspectiva de ação para o exercício da cidadania e dos princípios éticos, tende a ser ressignificada.

Segundo Silva (2012), "a socioeducação é uma política que tem como proposta a educação para a vida em liberdade", devendo efetivar-se a partir do que preconizam as legislações em relação às responsabilidades da família, da sociedade e do Estado, de modo a proporcionar condição para o desenvolvimento do adolescente autor de ato infracional enquanto sujeito de direitos.

A ação socioeducativa, sustentada nos princípios dos direitos humanos, encontra, de modo geral, dificuldade de compreensão e de aceitação. Tais situações são recorrentes, dado o desconhecimento do que a lei preconiza e dos valores intrínsecos à moral e aos costumes numa determinada sociedade. Se, por um lado, há a natureza sancionatória pela prática de um ato infracional, por outro, e ao mesmo tempo, há a necessidade da defesa do direito previsto e pactuado nacional e internacionalmente.

Não há dúvidas quanto aos avanços que estas legislações trouxeram no campo de atuação junto a esse público, ao menos do ponto de vista jurídico-formal, o que caracteriza ganhos na perspectiva de direitos. O paradigma da prioridade absoluta prevista na Constituição Federal e no Estatuto da Criança e do Adolescente é "uma normativa avançada e concretamente cidadã" (SALES, 2007, p. 14). Porém, a ideologia punitiva e repressiva, na prática, não sofreu grandes alterações. O discurso ideológico conservador ainda é constantemente suscitado nos mais diversos extratos 
da sociedade, especialmente quando se refere ao adolescente em cumprimento de medida privativa de liberdade - internação. No que se refere às prorrogativas de acesso aos bens que propiciam a efetividade de direitos, grande parcela dos adolescentes autores de ato infracional fica alijada.

Assim, o Estado brasileiro fez opção formal por um sistema de justiça juvenil calcado nos direitos fundamentais, com respeito a direitos e garantias individuais e com foco na promoção e proteção dos direitos humanos. Infelizmente, não e isso que se comprova na prática. (ALENCAR, 2010, p. 56).

As violações de direitos dentro das unidades de internação, no Brasil, ferem os princípios de dignidade humana e colocam questionamentos acerca do sistema socioeducativo do país. Segundo Alencar (2010, p. 56-57), referenciando o levantamento feito por membros do Conselho Federal de Psicologia e da Ordem dos Advogados do Brasil no ano de 2006, as violações mais acentuadas, na maioria dos estados brasileiros, são os espancamentos - por parte de policiais, no ato da apreensão ou enquanto os adolescentes aguardam em delegacias pela disponibilização de vagas em unidades socioeducativas; ausência de atividades escolares e profissionalizantes; alojamentos superlotados, insalubres, sem higiene e em condições precárias de habitabilidade; assistência jurídica deficiente; precariedade ou inexistência de atendimento à saúde; maus-tratos, torturas, entre outros.

Os últimos levantamentos sobre o atendimento socioeducativo nos anos de 2011 e 2012, realizado pela Secretaria de Direitos Humanos, dão conta de que são 452 unidades que executam as medidas restritivas e privativas de liberdade. 95\% delas destinam-se ao atendimento de adolescentes do sexo masculino e apenas 5\% atendem adolescentes do sexo feminino. Quanto às condições físicas das unidades e as adequações a partir do Sinase, $74,78 \%$ delas atendem parcialmente o que é preconizado, $16,74 \%$ são inadequadas e apenas $6,03 \%$ foram consideradas adequadas ao atendimento (BRASIL, 2012a, p. 30-46).

Observa-se, assim, que a prática de um ato infracional e a condição de privação de liberdade tendem a desqualificar o adolescente enquanto sujeito de direitos e com necessidades materiais e imateriais. O reconhecimento do ser cidadão, nesse contexto,

parece ser um exercício difícil e, para alguns, inapropriado. Neste contexto de indefinições crescem os preconceitos e alastram-se explicações simplistas, ficando a sociedade exposta a um amontoado de informações desencontradas e desconexas usadas para justificar o que no fundo não passa de uma estratégia de criminalização da pobreza, especialmente para os pobres de raça negra. (VOLPI, 2010, p. 9). 


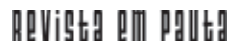

\} SERVIÇO SOCIAL E SOCIOEDUCAÇÃO - FERRAZ, T.; CESCONETO, E. A. \}

DOI: $10.12957 /$ REP.2016.27864

Este cenário de segregações é resultante de um modelo de sociedade que, historicamente, tem excluído esse público da seara de acesso aos bens necessários a uma vivência de forma digna. É inegável que a promulgação de legislações de âmbito nacional e internacional, implantadas ou implementadas através de pactos, convenções e declarações possibilitaram a construção de um novo modelo na política de atendimento aos adolescentes autores de ato infracional, na perspectiva de direitos humanos.

Quanto a este conceito - direitos humanos - não há consenso, mas há, entre os autores consultados, concordância de que, para que sejam absorvidos e efetivados numa determinada sociedade, necessitam, segundo Barroco (2011), de consentimento de âmbito político e social.

[...] os direitos sempre refletiram os estágios de desenvolvimento das sociedades. Os direitos são produtos históricos, resultantes da relação entre as demandas da sociedade civil. São oriundos da transformação social ocorrida por meio dos conflitos, lutas de classe, processos sociais e políticos que acompanham o desenvolvimento econômico da produção e da riqueza. (WENDHAUSEN, 2006, p. 128).

Dessa forma, o campo de lutas por direito se dá dentro de uma ordem burguesa, logo, também está submetido às determinações das bases constitutivas do capital que lhe serve como fundamento. Assim, as relações oriundas da contradição de uma sociedade de classes afetam o ordenamento jurídico.

São essas precondições que vão estruturar as relações em sociedade e que, não por acaso, constituirão as bases da estrutura econômica que se fundamenta na relação capital e trabalho. Portanto, "os direitos humanos não são [...] uma dádiva da natureza, um presente da história, mas fruto da luta contra o acaso do nascimento, contra os privilégios que a história até então vinha transmitindo hereditariamente" [...] (MARX, 1991, p. 38).

Não por acaso Marx (1975, p. 29), menciona que os chamados direitos humanos em sua forma autêntica, sob a forma que lhes deram seus descobridores norteamericanos e franceses, [nada mais são que] direitos políticos, direitos que só podem ser exercidos em comunidade e, concretamente, na comunidade política, no Estado. Esses direitos se inserem na categoria de liberdade política, na categoria de direitos civis [...] (apud FREIRE, 2013, p. 152).

Neste enfoque, a discussão sobre os fundamentos dos direitos humanos remete a uma reflexão sobre a emancipação humana que se configura na possibilidade de uma forma de expressão contrária às forças de uma ordem vigente. A alteração de um determinado direito não se dá apenas pela explicitação de ato jurídico, pois "o direito é a expressão de determinado patamar da materialidade", que se manifesta nas relações a partir de um contexto societário (IASI, 2013, p. 190). 


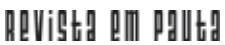

\} SERVIÇO SOCIAL E SOCIOEDUCAÇÃO - FERRAZ, T.; CESCONETO, E. A. \}

DOI: $10.12957 /$ REP.2016.27864

Também há consenso entre os autores pesquisados de que teria acontecido, a partir do século XVIII, a ampliação das discussões sobre os direitos humanos, ainda que apresentando limitações.

No momento em que os seres humanos se tornam supérfluos e descartáveis, no momento em que vige a lógica da destruição, em que cruelmente se abole o valor da pessoa humana, torna-se necessária a reconstrução dos direitos humanos, como paradigma ético capaz de restaurar a lógica do razoável. A barbárie do totalitarismo significou a ruptura do paradigma dos direitos humanos, por meio da negação do valor da pessoa humana como valor fonte de direito. Diante dessa ruptura, emerge a necessidade de reconstruir os direitos humanos, como referencial e paradigma ético que aproxime o direito da moral. (PIOVESAN, 2006, p. 116).

A reconstrução de novos paradigmas desses direitos é, segundo essa autora, uma importante resposta de repúdio às atrocidades cometidas contra pessoas no período das guerras. Além disso, deve ultrapassar o âmbito de poder de um estado, por se tratar de um problema de relevância internacional. Assim, a soberania estatal não é mais entendida como um princípio absoluto, estando sujeita a certos limites quando ferirem os direitos humanos. Na modernidade, a perspectiva sobre os direitos humanos

[...] representou um grande avanço no processo de desenvolvimento do gênero humano, pois, ao retirar os direitos humanos do campo da transcendência, evidenciou uma inscrição na práxis sócio-histórica [...]. Ao se apoiar em princípios e valores ético-políticos racionais, universais, dirigidos à liberdade e à justiça, a luta pelos direitos humanos incorporou conquistas que não pertencem exclusivamente à burguesia, pois são parte da riqueza humana produzida pelo gênero humano ao longo de seu desenvolvimento histórico, desde a antiguidade. (BARROCO, 2011, p. 55).

A história social dos direitos humanos é, segundo a autora, resultado da forma de organização da classe trabalhadora e de sujeitos políticos que, diante de um contexto de exploração e desigualdades, na segunda metade do século XIX passa a exigir tanto do Estado quanto do empresariado as condições mínimas para sua reprodução enquanto força de trabalho, amparados por direitos universais. E justamente a universalidade que constitui a novidade dos direitos humanos, porque reconhece a todas as pessoas, sem exclusão, a possiblidade do seu exercício.

Por outro lado, quando há a necessidade de reivindicação de um determinado direito, isto acontece porque, de certa forma, sua presença no cotidiano da vida social em sentido amplo e universal ainda se traduz numa abstração.

Nesse sentido, compreende-se que 
Os direitos humanos, mais que direitos 'propriamente ditos', são processos; ou seja, o resultado sempre provisório das lutas que os seres humanos colocam em prática para ter acesso aos bens necessários para a vida [...] Uma constituição ou um tratado internacional não criam direitos humanos [...] Os Direitos humanos são uma convenção que utilizamos para introduzir uma tensão entre os direitos reconhecidos e as práticas social que buscam tanto seus reconhecimento positivado como outra forma de reconhecimento. (FLORES, 2009, p. 34).

Considera-se, no entanto, a necessária atenção para o processo de construção e efetivação dos direitos que, na contemporaneidade, têm obtido avanços apenas no plano jurídico-formal, não se estendendo em sua plenitude mesmo pelos Estados-parte, inclusive pelo Brasil. Num contexto societário em que o modo de produção interfere diretamente nas relações sociais, políticas e principalmente econômicas, os direitos da pessoa humana enquanto discurso de universalidade tendem a ser subjugados a um plano secundário. A visão de direitos ancorada numa perspectiva neoliberal é concebida de forma abstrata, gerando uma pseudossensação de igualdade e impedindo a ampliação do campo de lutas pela concreta efetivação.

\section{A intervenção do assistente social no contexto socioeducativo: uma análise à luz dos direitos humanos}

O exercício de refletir sobre a atuação do assistente social na socioeducação, especificamente na medida de privação de liberdade, sob a perspectiva da defesa de direitos, implica um retorno às bases conceituais do Serviço Social, à legitimação e à fundamentação enquanto profissão no Brasil e no estado do Paraná. Além disso, também sobre o processo de redimensionamento e de reconhecimento enquanto classe trabalhadora inserida na divisão social e técnica do trabalho.

A partir das considerações de José Paulo Netto (1992), o Serviço Social, enquanto prática institucionalizada e legitimada, gesta-se num momento muito específico do processo capitalista constituído no trânsito à idade do monopólio. Isto é, as conexões genéticas do Serviço Social permeiam as peculiaridades da chamada "questão social" no âmbito da sociedade burguesa, consolidada e madura, que é fundada a partir da organização dos monopólios.

O capitalismo monopolista recoloca, em patamar mais alto, o sistema totalizante de contradições que confere à ordem burguesa os seus traços basilares de exploração, alienação e transitoriedade histórica. [...] A idade do monopólio altera significativamente a dinâmica inteira 
da sociedade burguesa: ao mesmo tempo em que potencia as contradições fundamentais do capitalismo já explicitadas no estágio concorrencial e as combina com novas contradições e antagonismos. (NETTO, 1992, p. 15).

Nesse sistema, a contradição existente na relação entre capital e trabalho se torna mais eminente, exigindo intervenção estatal na organização da vida econômica e agindo sobre as sequelas oriundas da exploração da força de trabalho da classe trabalhadora por parte da classe detentora dos meios de produção.

O Estado, nesse contexto, "é no nível das suas finalidades econômicas, o 'comitê executivo' da burguesia [...] que opera para propiciar o conjunto de condições necessárias à acumulação e à valorização do capital monopolista" (NETTO, 1992, p. 22). Age em resposta tanto às demandas da classe trabalhadora, dada a sua capacidade de mobilização e organização, quanto atua na defesa dos interesses econômicos da burguesia, por meio das políticas sociais. Estas, segundo esse autor, objetivam a intervenção estratégica e sistemática nas situações oriundas do modo de produção. Tais políticas operam como suporte econômico e sociopolítico respaldando a imagem do Estado, constituído como instrumento capaz de mediar os interesses conflitantes entre as classes.

O Serviço Social, enquanto profissão, emerge nesse contexto, num modo de produção e de reprodução das relações sociais, com interesses contraditórios, dada a correlação de forças entre as duas classes - burguesia e proletariado. Além de outros fatores, a emergência da profissão "é, em termos histórico-universais, uma variável da idade do monopólio [...] indivorciável da ordem monopólica - ela cria e funda a profissionalidade do Serviço Social" (NETTO, 1992, p. 70).

Embora o autor considere que a profissão seja erigida por esse projeto burguês, possibilitado a partir de uma ordem social com bases mercadológicas, daí a condição de assalariamento dos profissionais assistentes sociais, também considera que a dinâmica do projeto conservador que a engendra possibilita reformas que incidem e que interferem no âmbito das políticas sociais e econômicas em dado período da história e no processo de institucionalização da profissão.

O Serviço Social rompe com o estreito quadro de sua origem para se tornar uma atividade institucionalizada e legitimada pelo Estado e conjunto dominantes. Se era o caráter de missão de apostolado social e sua origem de classe que conferiam legitimidade à intervenção das 'pioneiras' do Serviço Social, agora a legitimidade da profissão virá do mandato institucional confiado ao assistente social, direta ou indiretamente, pelo Estado. (YASBEK et al., 1984, p. 48). 


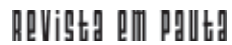

\} SERVIÇO SOCIAL E SOCIOEDUCAÇÃO - FERRAZ, T.; CESCONETO, E. A. \}

DOI: $10.12957 /$ REP.2016.27864

O vínculo com as instituições faz alterar, também, o modo de intervir do assistente social junto ao proletariado, atuando, prioritariamente, na execução de políticas sociais demandadas pelo Estado a tais setores.

O processo de revisão das bases conceituais do Serviço Social, iniciado na década de 1960, marca a história da profissão no Brasil e institui um novo direcionamento à atuação dos assistentes sociais. São vislumbrados horizontes a partir da vinculação com a classe trabalhadora, na perspectiva de luta por direitos sociais que serão previstos na Constituição Federal de 1988 e expressados nas políticas sociais de saúde, de previdência, de educação, de segurança, de trabalho, de moradia, de cultura e lazer, de assistência social, da criança e do adolescente, entre outras (CFESS, 2012, p. 24).

Essa opção coletiva da categoria pela construção de um novo projeto profissional contribuiu para a formulação e aprovação de várias legislações na década de 1990. Os assistentes sociais se colocam em várias frentes de lutas no sentido de defesa e de reafirmação de direitos, [...] "apoiando a participação qualificada dos sujeitos nas instâncias de representação coletiva e nas formas diretas de mobilização e organização social" (IAMAMOTO, 2012, p. 131).

A construção de um ordenamento jurídico positivado nesse período - e que tem continuidade nas décadas posteriores - foi significativa, considerando as suas características de universalidade. Contudo, é também veraz que, por ser construído a partir de um determinado contexto societário e histórico, pode sofrer avanços e retrocessos. Estes, conforme Chuairi (2001, p. 137), "não podem ser dissociados das metamorfoses do mundo contemporâneo, da situação de crise social e das consequências da modernidade no cotidiano da sociedade". Dessa forma,

A universalidade do direito, bandeira defendida arduamente pelo projeto da modernidade, esbarra na desigualdade e nas contradições próprias da realidade concreta, marcada pela luta de classes e por inúmeras formas de discriminação, opressão, dominação e exploração. [...] O direito é, portanto, um campo de disputas constantes. (CFÉSS, 2014, p. 19).

O sistema capitalista, pela própria lógica de que é composto, está ancorado em elementos do direito burguês, que promovem um contexto de desigualdades, desumanizam as relações e colocam empecilhos à sua efetiva realização. "A ausência de moradia digna, a ausência de trabalho e emprego com condições adequadas, privatização e mercantilização dos direitos como saúde são expressões da violência e da tortura" que estão se aperfeiçoando (CFESS, 2012, p. 17). Contudo, essa mesma lógica explicita a ideia de um modelo de sociedade em que a tônica é a universalidade do direito concebido, interferindo diretamente nas políticas sociais e na possibilidade de garantia de acesso a esse direito. Ou seja, expressa a contradição inerente à política social e à sociedade capitalista. 


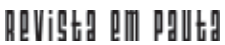

\} SERVIÇO SOCIAL E SOCIOEDUCAÇÃO - FERRAZ, T.; CESCONETO, E. A. \}

DOI: $10.12957 /$ REP.2016.27864

Nesse aspecto, sem o cuidado reflexivo sobre esses elementos, os profissionais podem, ao contrário de trabalhar pela supressão das "desigualdades sociais e de se assegurarem os direitos mínimos à vida, manter o fosso que aparta a humanidade de sua dignidade e repor-se a ordem social, na qual o desumano se funda" (BATISTA, 2013, p. 195).

Dessas considerações, tem-se que a intervenção do assistente social no âmbito da socioeducação se traduz numa constância de desafios que provocam e impelem esse profissional a novas estratégias em prol da defesa dos direitos do adolescente privado de liberdade, nas regiões Oeste e Centro-Oeste do estado do Paraná, que compreende os municípios de Cascavel, Foz do Iguaçu, Laranjeiras do Sul e Toledo.

A concepção de intervenção enunciada por Bidarra e Salata (2013, p. 215),

[...] traduz-se na dimensão mais instrumental de uma prática, isto é, a forma imediata e sensível desta se representar no campo da visibilidade, da aparência, do resultado. Contudo, na medida em que é portadora de um referencial teóricometodológico, toda intervenção é política porque está comprometida com a conservação ou superação de concepções do mundo, valores, princípios e normas de conduta. [...] A intervenção consiste na explicitação do que foi teleologicamente projetado para se traduzir como um momento da prática social ou da prática profissional. [...] Nesse sentido, a intervenção se apresenta no nível do imediato - aquilo que vemos e/ou sentimos.

Essa perspectiva destaca a importância do processo reflexivo sobre o reconhecimento da realidade do espaço sócio-ocupacional e suas repercussões nas intervenções realizadas pelos assistentes sociais na política da área da criança e do adolescente, especialmente no contexto de um dos programas de atendimento socioeducativo, qual seja, da privação de liberdade.

Para tanto, considerou-se importante apresentar o perfil dos profissionais de Serviço Social que atuam nos centros de socioeducação participantes desta pesquisa, como sujeitos da interlocução sobre as condições em que se realizam a socioeducação em meio fechado, nas regiões citadas. Todos são do gênero feminino, com idades entre 32 e 51 anos. Possuem graduação em Serviço Social e especialização lato sensu. Uma delas concluiu a pós-graduação stricto sensu, em nível de mestrado. O vínculo empregatício é estatutário, com jornada de trabalho de 40h semanais, sendo oito horas diárias, podendo ocorrer também nos finais de semana, por ocasião das visitas de familiares de adolescentes internados. O tempo de atuação no contexto do atendimento socioeducativo varia de nove meses a 20 anos.

Consideraram-se pertinentes as informações obtidas a partir dos relatos dos sujeitos entrevistados em relação à composição das equipes nos 


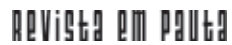

\} SERVIÇO SOCIAL E SOCIOEDUCAÇÃO - FERRAZ, T.; CESCONETO, E. A. \}

DOI: $10.12957 /$ REP.2016.27864

Censes, uma vez que estas demonstram como os recursos humanos disponíveis interferem na oferta qualificada do atendimento aos adolescentes privados de liberdade. Mediante os dados coletados, constatou-se que não há equipe completa em nenhuma dessas unidades de internação e que outros profissionais poderiam ser incluídos na equipe, dadas as demandas existentes.

Com relação à inclusão de outros profissionais na composição das equipes, o artigo 12 do Sinase (BRASIL, 2012b) preconiza que há essa possibilidade, de modo a suprir as necessidades dos programas de atendimento. Contudo, até o período da coleta de dados para a pesquisa não havia previsão de contratação e/ou de incorporação de profissionais nas unidades socioeducativas. A falta desses profissionais faz com que a gestão estadual busque alternativas que nem sempre são as mais adequadas, como no caso dos remanejamentos e/ou cedências de profissionais. $O$ déficit de recursos humanos na composição das equipes tende a dificultar a realização de um trabalho qualificado, tornando falho o desenvolvimento de ações potencializadoras de um processo de "consciência de si" e de protagonismo dos adolescentes que cumprem a medida socioeducativa de internação. Da mesma forma, os reflexos da sobrecarga de atividades (rotineiras e desgastantes) afetam os demais trabalhadores no cotidiano das intervenções, os quais acabam desenvolvendo um sentimento de descrença no potencial e na capacidade de estabelecer novos direcionamentos para a vida.

Raras são as pessoas que não se deixam intoxicar por esse cotidiano. Raras são as pessoas que o rompem ou suspendem, concentrando todas as suas forças em atividades que as elevem deste mesmo cotidiano e Ihes permita a sensação e a consciência do ser homem total, em plena relação com o humano e a humanidade de seu tempo. (CARVALHO; NETTO, 2011, p. 23).

A pesquisa de campo realizada captou esse sentimento entre os profissionais que atuam nas unidades socioeducativas. Muitos deles revelaram as dificuldades para não se deixarem envolver e se "intoxicar" por esse emaranhado que, na sua sutileza, vai embrutecendo as pessoas, tornando-as descrentes e isentas de sentimento de humanidade.

Nesse sentido, "a desesperança na possibilidade de os homens coletivamente desejarem, quererem e realizarem a transformação do mundo em direção a uma plena humanização" (CARVALHO; NETTO, 2011, p. 43 - grifos no original) gera um vazio no cotidiano das relações.

A rotina é parte determinante no exercício profissional do assistente social. Por um lado, possibilita a organização e a avaliação das atividades desenvolvidas, bem como a identificação das atividades por parte dos usuários; mas, por outro, pode distanciar o profissional daquilo que ele faz, uma vez que mecaniza as ações. O fazer por 
repetição pode levar à desqualificação daquilo que é próprio do exercício profissional do assistente social: a necessária relação entre o pensar e a ação, entre a análise e a intervenção. (TORRES, 2009, p. 214).

Esse é um processo perigoso, pois, a partir do momento em que se perde a capacidade de importar-se com a subjetividade do outro, especialmente quando esse outro é um adolescente, perde-se também a oportunidade de criar e possibilitar o acesso a processos reflexivos e transformadores. Logo, essa "desistência" em projetar alternativas para as trajetórias de vida desses adolescentes também pode vir a ser considerada como um aspecto violador de direitos desses sujeitos.

No que tange à perspectiva de direitos humanos, os assistentes sociais têm a clareza de que suas ações buscam alinhar-se à previsão legal da área da socioeducação, tanto em relação às políticas sociais, e dentre elas a política da criança e do adolescente, quanto às normativas que regem a profissão. Apesar disso, nem sempre uma intervenção alinhada pode ser suficiente para que se garanta que os direitos humanos sejam materializados.

Vê-se o reconhecimento de que se convive com a distância entre a previsão legal e o que se realiza no cotidiano das unidades socioeducativas, confirmando que ainda são seguidos os referenciais que não coadunam com a perspectiva de direitos. Ou seja, pouco se avançou para concretizar os referenciais de Beijing, Riad, Estatuto e Sinase.

Os assistentes sociais entrevistados demonstram o desejo de mudanças e lutam para a melhoria de algumas condições no atendimento a esse público. No entanto, esbarram na disputa entre saberes instituídos e expressos pelos membros das equipes, o que dificulta o atendimento às necessidades do adolescente que, em muitos casos, está aquém daquilo que é recomendado e almejado pelos profissionais.

Essa parcialização do acesso aos direitos é constructo de uma sociedade burguesa que explicita um discurso de universalização expresso por meio de aparatos jurídico-formais, como resposta aos reclames da classe trabalhadora, mas que, ao mesmo tempo, o restringe.

Nesse sentido, concorda-se com Vieira (2004, p. 30) de que "não há direito sem sua materialização. A prática de direitos, mecânica e superficialmente, desprovida da mínima noção de sua existência, gera insensibilidade moral, conformismo e negação deles próprios".

Há também, entre os profissionais, uma nítida compreensão de que o acesso a um determinado direito perpassa questões de ordem estrutural e que o contexto no qual o sujeito está inserido pode determinar algumas condições para o exercício ou não desses direitos.

É reveladora a percepção das entrevistadas de que a cultura institucional, além de não estar alinhada à perspectiva de direitos, por vezes é também violadora desses. Os movimentos para que haja esse alinhamento 


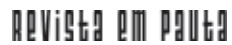

\} SERVIÇO SOCIAL E SOCIOEDUCAÇÃO - FERRAZ, T.; CESCONETO, E. A. \}

DOI: $10.12957 /$ REP.2016.27864

são reconhecidos, mas perpassados por muitas dificuldades devidas à ênfase que se dá aos aspectos relacionados à segurança. Ou seja, no cotidiano das unidades socioeducativas há, de acordo com Kosik (2002), uma pseudoconcretização dos direitos.

O não alinhamento da cultura institucional em prol do acesso aos bens necessários para que o adolescente não apenas cumpra uma determinação de sentença judicial, mas que consiga estabelecer novos parâmetros de convívio societário é objeto de uma luta árdua no cotidiano interventivo do assistente social. A todo tempo, por mínima que seja uma proposta de ação que sugira qualquer alteração na rotina, vive-se o processo desgastante de convencimento dos sujeitos que operam esse sistema, os quais nem sempre demonstram vontade e disponibilidade para que a mudança aconteça. Por vezes, além de se eximirem das responsabilidades, ainda colocam empecilhos à sua realização. A cultura da segurança é predominante nesses espaços. As premissas de uma proposta pedagógica de atendimento socioeducativo ocorrem, mas sempre dentro de um contexto limitador.

O convívio e a resistência contra os processos de desumanização ainda presentes nas unidades socioeducativas exigem do assistente social o posicionamento e o planejamento de ações que possam se contrapor à realidade cotidiana expressa nesses espaços. A não observância de tais processos resulta numa leitura simplificada da realidade e alimenta uma consciência crítica frágil "de processos de despolitização, de incorporação de valores e de ideologias conservadoras, [...] que vem sendo agravado na conjuntura atual" (BARROCO; TERRA, 2012, p. 75).

Em nenhuma das unidades investigadas foi identificado um plano de ação específico do Serviço Social, mas sim um cronograma de atividades construído coletivamente por todos os atores das unidades, dos quais o assistente social pode fazer parte. Contudo, este é considerado importante, na medida em que possibilita o desvendamento da realidade com a qual atua, permitindo o conhecimento das implicações que afetam no cotidiano as ações junto ao adolescente privado de liberdade. Permite o conhecimento do seu objeto de intervenção, auxilia no processo de definição das prioridades e tende a facilitar o alcance dos objetivos propostos.

Há o reconhecimento da necessidade de registro e de planejamento das ações específicas do Serviço Social na instituição e percebe-se que sua ausência dificulta a coleta de dados e a sistematização de informações sobre a realidade social na qual está intervindo, podendo impossibilitar a construção de respostas viáveis e efetivas de modo a conduzir o atendimento às demandas dos adolescentes na perspectiva da defesa de direitos. A disponibilidade de tempo para o estudo e para o planejamento de ações se constitui, com base nos depoimentos, num dos desafios a serem vencidos pela categoria dentro da instituição. 


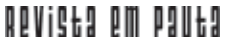

\} SERVIÇO SOCIAL E SOCIOEDUCAÇÃO - FERRAZ, T.; CESCONETO, E. A. \}

DOI: $10.12957 /$ REP.2016.27864

Outro aspecto presente na pesquisa é a não identificação, por parte dos sujeitos, de estratégias específicas do Serviço Social nas unidades socioeducativas, denotando as seguintes questões: a predominância da ação interdisciplinar (que não anula as individualidades) e o excesso de tarefas, que concorre para tornar o trabalho desse profissional mais imediatista, em detrimento de uma ação pensada enquanto práxis. Esta ação se constitui num desafio para o cotidiano da intervenção do assistente social, dadas as angústias experimentadas diante de situações desafiadoras, como: falta de clareza dos objetivos do Serviço Social na instituição, falta de recursos humanos, de capacitações continuadas e de previsão orçamentária para a realização e predominância de uma cultura institucional pautada nos aparatos ideológicos punitivos.

A estrutura física das unidades e as condições de trabalho foram citadas como complicadores para o atendimento por violarem não apenas o direito do adolescente, mas também das famílias e do próprio profissional, não dispondo de espaço adequado para o atendimento.

As questões relacionadas ao espaço físico podem comprometer, dentre outros, o sigilo no âmbito de atuação do assistente social, conforme preconizado nos artigos 15 a 18 do Código de Ética da Profissão (1993). (BARROCO; TERRA, 2012).

Aqui, esclarece-se que, em relação à infraestrutura, as unidades de Cascavel e de Laranjeiras do Sul foram construídas de acordo com um novo modelo arquitetônico previsto, a partir de 2004, e embasado em Beijing e Riad. Em vista disso, em tais unidades não foram identificados maiores problemas. No entanto, nas unidades de Toledo e de Foz do Iguaçu, que são mais antigas e constituíram-se a partir de adaptações e reformas, a situação é mais complicada, o que dificulta o desenvolvimento de ações dentro das condições necessárias ao desempenho de suas funções.

A adequação de espaços para atendimento ao adolescente e à família foi considerada, mas tem-se a clareza de que uma estrutura física adequada não se traduz em garantia de atendimento de qualidade. A mudança de paradigmas está além da colocação de tijolos e da destinação de salas de atendimento individual. O que se coloca ao assistente social no exercício de suas funções envolve uma evidente correlação de forças e de divergências teóricas entre os que atuam no interior desses estabelecimentos.

Por vezes, os registros das insuficiências aparecem como desabafo daqueles que vivem as pressões de um cotidiano em unidade de privação de liberdade, a qual "é marcada por um processo de lutas e contradições" (SIMAS; RUIZ, 2015, p. 86), nos quais valores e ideais, sejam das normativas relativas à socioeducação, sejam do projeto ético-político da profissão, são impactados por decisões difíceis e complexas para a defesa dos direitos da população usuária desse serviço. A partir dos dados obtidos com esse processo investigativo, considera-se que os profissionais atuantes nesses espaços têm a clareza da necessidade de reflexão teórica sobre o contexto socioedu- 


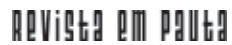

\} SERVIÇO SOCIAL E SOCIOEDUCAÇÃO - FERRAZ, T.; CESCONETO, E. A. \}

DOI: $10.12957 /$ REP.2016.27864

cativo e se angustiam diante da rotina institucional adversa a isso. A afirmação de espaços reflexivos e de tempo para estudo, especialmente sobre socioeducação, se constitui num desafio por não depender apenas desse profissional, mas de uma política institucional que invista na ampliação de conhecimentos em relação aos parâmetros que regem o contexto socioeducativo.

É fundamental que as capacitações sejam ofertadas pela secretaria e que haja investimento nessa área. A falta de discussão/formação permanente em relação às práticas no contexto socioeducativo, aliada aos ínfimos recursos investidos nos trabalhadores que atuam nesses espaços, tende a um "perigoso" processo de naturalização e de banalização de formas de violências e outras questões relacionadas ao desenvolvimento do ser social. Ou seja, tende a tornar os sujeitos envolvidos nesse processo menos sensíveis e capazes de admitir como válidas as necessidades manifestas pelos adolescentes.

A contribuição desse profissional para o contexto socioeducativo se torna imprescindível para que os sujeitos sejam reconhecidos enquanto ser social. Embora limitadas pela realidade institucional, são necessárias frentes de lutas para que esses adolescentes tenham acesso aos bens necessários para cumprir a medida socioeducativa de internação com um mínimo de dignidade. Nesse sentido, a intervenção profissional nesse espaço sócio-ocupacional demanda firmeza de posicionamentos e compromisso ético em prol do acesso e da satisfação das necessidades humanas, especialmente do adolescente em cumprimento de medida socioeducativa.

\section{Considerações finais}

A intervenção do assistente social junto a adolescentes autores de ato infracional, na perspectiva de defesa de direitos humanos, e a construção dos aparatos jurídico-formais, não são recentes e seguem os parâmetros da dinâmica social em determinado tempo da história.

Muitas das legislações aprovadas em tempos recentes e que expressam esses direitos, são concebidas no âmbito do caráter restritivo de direitos compatível com a perspectiva neoliberal. Assim sendo, mesmo que se reportem à nobreza de objetivos universalistas, segundo Colombo (2006), não dispõem de condição efetiva de aplicabilidade. São abstratos e segmentados, não sendo possível seu usufruto por todo e qualquer cidadão. Logo, não mudam as realidades caso os sujeitos inseridos nesse processo não disponham de condições próprias e sejam capazes de ultrapassar a inércia a que são levados pelo seu cotidiano.

No contexto socioeducativo, as situações de violações que ferem o princípio da dignidade humana ainda persistem. A partir da análise dos dados apresentados, tem-se um cenário com perigoso indício de retrocesso na intervenção junto aos adolescentes autores de ato infracional. Apesar 


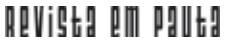

\} SERVIÇO SOCIAL E SOCIOEDUCAÇÃO - FERRAZ, T.; CESCONETO, E. A. \}

DOI: $10.12957 /$ REP.2016.27864

dos avanços obtidos enquanto direito positivado, há ainda muitos problemas a serem superados nesses espaços.

Os assistentes sociais que atuam nos referidos ambientes reconhecem que suas ações estão amparadas pela previsão legal e buscam, mediante elas, viabilizar o acesso aos direitos dos usuários dessa política. Entretanto, compreendem que a materialização está muito aquém das suas expectativas. Não raras vezes, são levados a enfrentamentos de posições ideológicas contrárias à previsão de direitos, que dificultam, assim, o desenvolvimento de melhorias nas condições de atendimento a esse público.

A ação socioeducativa, sustentada nos princípios dos direitos humanos, de modo geral, encontra dificuldade de compreensão e de aceitação quanto aos objetivos a que se propõe: se, por um lado, está presente a natureza sancionatória da medida socioeducativa ao adolescente que praticou um ato infracional, por outro e, ao mesmo tempo, há a necessidade da previsão legal pactuada em âmbito nacional e internacional pela defesa de direitos.

Encontrar novas possibilidades de intervenção nessa realidade, de modo que se ampliem o conhecimento e a compreensão em relação ao significado do conceito (ou noção) de socioeducar, é, para os assistentes sociais que atuam nas unidades de privação de liberdade, um dos desafios a serem superados, considerando a lógica da vigilância e dos aparatos coercitivos que marcam o cotidiano dentro desses espaços institucionais. $\mathrm{O}$ entendimento de que a privação de liberdade suprime do adolescente os demais direitos inerentes à sua condição humana ainda persiste.

Esse processo é favorecido por uma cultura institucional que oscila entre a proteção e a violação de direitos. As condições objetivas de trabalho do assistente social nesses espaços dificultam o processo de superação de questões relacionadas com a possibilidade de acesso aos bens sociais, necessários e favorecedores ao desenvolvimento da dignidade humana.

A intervenção do assistente social, nesse contexto, é perpassada por uma realidade complexa e contraditória que busca se equilibrar na linha tênue que divide o caráter socioeducativo e o repressivo/punitivo da medida, presentes e concorrentes nas instituições de privação de liberdade.

A pesquisa apontou como desafiadora e desgastante a luta para ultrapassar o processo de rotinização das atividades e o excesso de tarefas decorrentes do déficit de recursos humanos presente nesses espaços, corroborando para que profissionais assumam responsabilidades que nem sempre são de sua alçada. Além disso, há estruturas físicas inadequadas, o que fere a qualidade dos atendimentos ao público usuário desse serviço, bem como a não viabilização de capacitações por parte da secretaria e a insuficiência de recursos financeiros para atender às necessidades dos adolescentes, das famílias e da equipe de modo geral.

Aliado a isso, o posicionamento a partir de um referencial teóricocrítico se constitui em mais uma alternativa capaz de imprimir um novo 


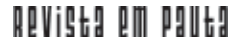

\} SERVIÇO SOCIAL E SOCIOEDUCAÇÃO - FERRAZ, T.; CESCONETO, E. A. \}

DOI: $10.12957 /$ REP.2016.27864

direcionamento e um novo significado à sua atuação nas unidades socioeducativas, mas a fragilidade dos aportes teórico-metodológicos tende a dificultar (ou até mesmo a impossibilitar) a superação de um cotidiano permeado por questões violadoras de direitos.

O assistente social se reconhece como o profissional da intervenção que cobra respostas, denuncia, faz mediações e tem consciência de seu papel nesse contexto de lutas. Contudo, há também clareza de que os desafios que se colocam à intervenção profissional nesses espaços são respostas do predomínio de uma cultura pautada na construção ideológica de um estado penal que potencializa o ato de punir e que nega a possibilidade de exercício pleno de direitos.

Com isso, percebe-se a necessidade de que esse profissional disponha de competência técnica, ética e política para tornar possíveis as respostas às demandas oriundas de expressões da questão social, tendo por base um direcionamento ético em prol do exercício do direito do ser adolescente, quando em privação de liberdade. 


\section{Referências}

ALENCAR, V. S. Justiça juvenil: repressão e violação de direitos. Pucviva, n. 39, 2010.

BARROCO, M. L. S. A historicidade dos direitos humanos. In: FORTI, V.; GUERRA, I. (Org.). Ética e direitos: ensaios críticos. Rio de Janeiro: Lumen Juris, 2011.

BARROCO, M. L. S.; TERRA, S. H. Código de ética do/a assistente social comentado. São Paulo: Cortez, 2012.

BATISTA, M. I. F. C. e S. Os direitos humanos, suas contradições e limites na sociedade capitalista. In: FABRIS, D. R.; CESCONETO, E. A.; SMAHA, I. N. (Org.). 25 anos do curso de Serviço Social da Unioeste: diálogos e reflexões no contexto dos direitos humanos. Cascavel: Edunioeste, 2013.

BIDARRA, Z. S.; ROESLER, M. R. V. B. Socioeducação: reflexões para a construção de um projeto coletivo de formação cidadã. Cascavel: Edunioeste, 2011.

BIDARRA, Z. S.; SALATA, C. P. Intervenção Profissional Pautada no Referencial dos Direitos Humanos, na Política de Garantia dos Direitos da Criança e do Adolescente. In: FABRIS, D. R.; CESCONETO, E. A.; SMAHA, I. N. (Org's.). 25 anos do Curso de Serviço Social da Unioeste: diálogos e reflexões no contexto dos direitos humanos. Cascavel: Edunioeste, 2013. p. 207-222.

BRASIL. Constituição da República Federativa do Brasil. Brasília, 1988.

. Lei Federal n. 8.069 de 13 de julho de 1990. Dispõe sobre o Estatuto da Criança. 1990. Disponível em: <http://www.planalto.gov.br/ccivil_03/ leis/l8069.htm>. Acesso em: 15 jun. 2014.

. Sistema Nacional de Atendimento Socioeducativo (Sinase). Brasília: Secretaria Especial dos Direitos Humanos, 2006. Disponível em: <http:// www.condeca.sp.gov.br/legislacao/sinase_integra.pdf.>. Acesso em: 13 jul. 2014.

. Secretaria de Direitos Humanos. Brasília, 2012a. Disponível em: <http://www.sdh.gov.br/assuntos/criancas-e-adolescentes/pdf/Sinase Levantamento2011.pdf.>. Acesso 6 abr. 2015.

Sistema Nacional de Atendimento Socioeducativo (Sinase). Brasília, 2012b. Disponível em: <http://www.planalto.gov.br/ccivil_03/_Ato20112014/2012/Lei/L12594.htm.>. Acesso em: 9 jul. 2012.

CARVALHO, M. do C. B. de; NETTO, J. P. Cotidiano: conhecimento e crítica. São Paulo: Cortez, 2011. 
CFESS. Il Seminário nacional: o Serviço Social no campo sociojurídico na perspectiva da concretização de direitos. Brasília: CFESS, 2012.

. Atuação de assistentes sociais no sociojurídico. Subsídios para reflexão. Brasília: CFESS, 2014.

CHUAIRI, S. H. Assistência jurídica e serviço social: reflexões interdisciplinares. In: Revista Serviço Social e Sociedade, São Paulo, n. 67, p. 124-144, 2001.

COLOMBO, I. Adolescência infratora paranaense: história, perfil e prática discursiva. Tese (Doutorado - História). Universidade de Brasília, Brasília, 2006. Disponível em: <http://repositorio.unb.br/bitstream/10482/2782/1/ 2006_Irineu\%20Colombo.pdf>. Acesso em: 10 out. 2014.

COSSETIN, M. Socioeducação no estado do Paraná: os sentidos de um enunciado necessário. Dissertação (Mestrado - Educação). Universidade Estadual do Oeste do Paraná (Unioeste), Cascavel, 2012. Disponível em: $<$ http://projetos.unioeste.br/pos/media/File/educacao/Dissertacao_marcia _cossetin.pdf.>. Acesso em: 29 mar. 2015.

COUTINHO, C. P. Métodos de investigação em educação. Estudo de caso. Portugal: Universidade do Minho, 2008. Disponível em: <grupo4te.com. sapo.pt/estudocaso>. Acesso em: 22 abr. 2014.

FLORES, J. H. A reinvenção dos direitos humanos. Florianópolis: Fundação Boiteux, 2009.

FREIRE, S. de M. Direitos humanos no Brasil: ilusão jurídica ou possibilidade histórica? In: FORTI, V.; BRITES, M. C. (Org.). Direitos humanos e Serviço social: polêmicas, debates e embates. Rio de Janeiro: Lumen Juris, 2013.

IAMAMOTO, M. V. A fé no que virá e a alegria de olhar para trás: 30 anos do projeto ético-político profissional. In: SEMINÁRIO NACIONAL: 30 ANOS DO CONGRESSO DA VIRADA. Brasília: CFESS, 2012.

IASI, M. L. O direito e a luta pela emancipação humana. In: FORTI, V.; BRITES, C. M. Direitos humanos e Serviço Social: polêmicas, debates e embates. Rio de Janeiro: Lumen Juris, 2013.

KOSIK, K. Dialética do concreto. São Paulo: Paz e Terra, 2002.

MARX, K. Questão judaica. São Paulo: 1991.

NETTO, J. P. Capitalismo monopolista e Serviço Social. São Paulo: Cortez, 1992.

PIOVESAN, F. Direitos humanos e o direito constitucional internacional. São Paulo: Saraiva, 2006.

PIZATO, E. Famílias de adolescentes privados de liberdade: uma problemática em questão no Cense de Toledo (PR). 2011. Disponível em: < 


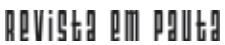

\} SERVIÇO SOCIAL E SOCIOEDUCAÇÃO - FERRAZ, T.; CESCONETO, E. A. \}

DOI: $10.12957 /$ REP.2016.27864

http://cac-php.unioeste.br/cursos/toledo/servico_social/arquivos/2011/ ELAINE_PIZATO.pdf>. Acesso em: 5 dez. 2015.

SALES, M. A. (In)visibilidade perversa - adolescentes infratores como metáfora da violência. São Paulo: Cortez, 2007.

SILVA, S. C. Socioeducação e juventude: reflexões sobre a educação de adolescentes e jovens para a vida em liberdade. Serviço Social em Revista, Londrina, v. 14, 2012. Disponível em: <http://www.uel.br/revistas/uel/index .php/ssrevista/article/view/8398>. Acesso em: 28 ago. 2016.

SIMAS, F. do N.; RUIZ, J. L. de S. Exercício profissional: uma mediação central entre direitos humanos e o projeto ético-político do serviço social brasileiro. In: GUERRA, V. L.; DEMÉTRIO, I. A. (Org.). Projeto ético-político do Serviço Social: contribuições à sua crítica. Rio de Janeiro: Lumen Juris, 2015.

TORRES, M. M. As múltiplas dimensões presentes no exercício profissional do assistente social: intervenção e o trabalho socioeducativo. Serviço Social em Revista, Londrina, v. 12, jul./dez. 2009.

VIEIRA, E. Os direitos e a política social. São Paulo: Cortez, 2004.

VOLPI, M. O adolescente e o ato infracional. São Paulo: Cortez, 2010.

WENDHAUSEN, E. J. Pensando os direitos humanos como formadores de capital social: o trabalho infanto-juvenil na cultura de arroz no estado de Sergipe. Revista Serviço Social e sociedade, ano XXV, n. 86, jul. 2006.

YASBEK, M. C. et al. Projeto de revisão curricular da Faculdade de Serviço Social - PUC-São Paulo. Serviço Social e Sociedade, São Paulo: Cortez, n. 14, 1984.

ZANIANI, E. J. M. Criminalidade infantil: a "endemia traiçoeira" do Brasil republicano. In: BOARINI, M. L. (Org.) Higiene mental: ideias que atravessam o século XX. Maringá: Eduem, 2012.

Recebido em 20 de abril de 2016.

Aprovado para publicação em 21 de julho de 2016.

DOI: $10.12957 /$ rep.2016.27864

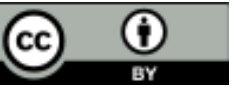

A Revista Em Pauta: Teoria Social e Realidade Contemporânea está licenciada com uma Licença Creative Commons Atribuição 4.0 Internacional. 